Article

\title{
Does Brain Lateralization Affect the Performance in Binary Choice Tasks? A Study in the Animal Model Danio rerio
}

\author{
Maria Elena Miletto Petrazzini ${ }^{1, *}$, Alessandra Pecunioso ${ }^{2}$, Marco Dadda ${ }^{2}$ \\ and Christian Agrillo 2,3 \\ 1 Department of Biomedical Sciences, University of Padova, Via Bassi 58-b, 35131 Padova, Italy \\ 2 Department of General Psychology, University of Padova, Via Venezia 8, 35131 Padova, Italy; \\ alessandra.pecunioso@studenti.unipd.it (A.P.); marco.dadda@unipd.it (M.D.); \\ christian.agrillo@unipd.it (C.A.) \\ 3 Padua Neuroscience Center, University of Padova, Via 8 Febbraio 2, 35122 Padova, Italy \\ * Correspondence: m.e.milettopetrazzini@qmul.ac.uk or mariaelena.milettopetrazzini@gmail.com
}

Received: 30 May 2020; Accepted: 31 July 2020; Published: 4 August 2020

\begin{abstract}
Researchers in behavioral neuroscience commonly observe the behavior of animal subjects in the presence of two alternative stimuli. However, this type of binary choice introduces a potential confound related to side biases. Understanding whether subjects exhibit this bias, and the origin of it (pre-existent or acquired throughout the experimental sessions), is particularly important to interpreting the results. Here, we tested the hypothesis according to which brain lateralization may influence the emergence of side biases in a well-known model of neuroscience, the zebrafish. As a measure of lateralization, individuals were observed in their spontaneous tendencies to monitor a potential predator with either the left or the right eye. Subjects also underwent an operant conditioning task requiring discrimination between two colors placed on the left-right axis. Although the low performance exhibited in the operant conditioning task prevents firm conclusions from being drawn, a positive correlation was found between the direction of lateralization and the tendency to select the stimulus presented on one specific side (e.g., right). The choice for this preferred side did not change throughout the experimental sessions, meaning that this side bias was not the result of the prolonged training. Overall, our study calls for a wider investigation of pre-existing lateralization biases in animal models to set up methodological counterstrategies to test individuals that do not properly work in a binary choice task with stimuli arranged on the left-right axis.
\end{abstract}

Keywords: lateralization; side bias; fish; methodological artefacts; symmetry

\section{Introduction}

In the last three decades, an increasing number of studies have been reported in the field of behavioral neuroscience that are based on animal models. The observation of spontaneous behavior assessed through the use of free choice tests [1,2] or the study of learned abilities as a result of operant conditioning studies [3-5] shed light on the perceptual-cognitive mechanisms of vertebrates. For both methodological approaches, animals typically undergo binary choices with stimuli presented on the left-right axis [6-9]. These are usually either two biologically relevant stimuli (e.g., pieces of food or conspecifics, in the case of free choice tests $[7,10,11]$ ) or two sets of neutral stimuli (e.g., two-dimensional figures or pictures, in the case of operant conditioning studies $[8,9,12])$. In both types of studies, it is not rare to find subjects that repeatedly select the stimulus presented on one specific side (e.g., always the right one). This effect is referred to as side bias or side preference [13,14], which is the tendency to select one alternative stimulus over others even though there is not any 
identified reason, and belongs to the category of idiosyncratic choice biases [15]. Such biases have also been widely observed in human research (e.g., [15]) and may represent a potential confounding factor that affects the conclusions of an experiment. For instance, Andrade et al. [16] found that rats commonly show left or right bias in spontaneous arm preference in a T-maze, a fact that might have impacted the conclusions of several studies on spatial abilities, learning, and memory in rats tested with this type of apparatus. Understanding the reason for a consistent preference for a stimulus placed on the same side of the apparatus is fundamental. A random choice between two stimuli, whose presentation is counterbalanced across trials between left and right, might be due to two opposite reasons: subjects might not have the cognitive abilities to discriminate between the two stimuli, or they might display such cognitive skills but have side biases that prevent the experimenters from testing their hypotheses. Dissociating between these two alternative explanations is necessary for interpreting subjects' performance.

Side biases might have at least two different origins. First, they might be the result of the experimental context. For instance, due to a repeated number of stimulus presentations used in operant conditioning studies, animals might have started to develop a preference for one side of the apparatus (e.g., $[17,18]$ ) because this strategy permits obtaining food rewards approximately $50 \%$ of the time (avoiding any need to understand which is the discriminative cue between two stimuli). Second, side biases may be present at the onset of the training because of an intrinsic side preference of the subjects [19-23]. Recently, it has been suggested that, at least in human participants, this type of bias might emerge regardless of the peculiarity of the experimental context or procedure, or any kind of pre-existing side preferences of the individuals. By investigating computational models of decision-making, Lebovich et al. [15] found that idiosyncratic choice biases may emerge naturally from the neural circuits underlying decision-making. In this sense, they would represent a virtually inevitable side effect of all binary choice tasks. A recent study requiring rhesus monkeys to choose between two colors by making saccadic movements [24] suggested that when the reward is unpredictable (for instance, when food items are randomly assigned to the two colors), animals may start to exhibit sub-optimal exploratory behaviors, which would be the result of very slow learning, or reward memory, in the attempt to face the unpredictability of non-stationary environments.

Side biases related to the experimental context or procedure can be partially adjusted, for instance, by adopting a correction procedure, such as presenting the target stimulus on the non-preferred side of the subject, to correct their acquired tendency to turn in one direction. On the contrary, side biases related to pre-existing preferences of subjects might be more difficult to modify if stimuli are exclusively arranged on the left-right axis. Therefore, it becomes fundamental to discriminate the type of side bias (spontaneous vs. acquired) observed in a binary choice task.

Intrinsic side bias is believed to be the result of brain lateralization. Functional brain asymmetries were initially thought to be a human peculiarity, but evidence collected in the last few decades has shown that the asymmetries are a widespread principle of nervous system organization. Functional right-left brain asymmetries have been found in a wide range of species [25-31]. For instance, when exploring a predator, some fish species exhibit a preference for monitoring it with a specific eye [32], as a result of a brain specialization that allows them to encode predators' features with one particular side of the brain (the one contralateral to the eye used to inspect the predator). The possibility exists that strongly lateralized individuals are more susceptible to side biases in binary choices than poorly lateralized ones [33].

In the last few decades, the teleost fish Danio rerio—also known as zebrafish-has become one of the most adopted models in genetics, neuroscience, and developmental biology [34,35]. Despite the wide range of neurobiological investigations, the cognitive skills of this species remain largely unknown. Only recently, the methodology for the study of cognition in zebrafish has been improved, a fact that permitted the discovery of the existence of numerical [36,37], spatial [38,39], and perceptual [40,41] abilities in this species. Zebrafish also exhibit a wide range of lateralized behaviors, including conspecifics inspection [42], escape response [43], and foraging behavior [44]. However, no study has 
directly focused on the relation between brain lateralization and side bias in binary choices of this important animal model.

Here, we tested the hypothesis according to which lateralized individuals are more likely to exhibit side biases than poorly lateralized ones in a binary choice test. To achieve this goal, we observed zebrafish behavior in both a spontaneous choice task and an operant conditioning task. To assess the degree of lateralization of subjects, we used a test known as a detour test $[32,45,46]$ that sheds light on the spontaneous preference for the use of one eye (and, hence, one side of the brain) in the presence of a potential predator. The same subjects were observed in a color discrimination task. They were required to discriminate between two rectangles differing in color, one placed on the right and one placed on the left, to obtain a food reward. Unlike many other training studies on cold-blooded vertebrates $[47,48]$, here we used an automated procedure to guarantee extensive training comparable to that used with mammals and birds. This permitted us to establish whether side biases are acquired throughout the experimental sessions because of the prolonged presentation of stimuli. We correlated the behavior in the detour test to the choices for one side of the experimental tank of the color discrimination task to see whether there was any significant link between brain lateralization and performance in the operant conditioning task.

\section{Methods}

\subsection{Subjects}

We tested 16 adult zebrafish ( 9 females, with approximate ages of 8-14 months). Fish were maintained at the comparative psychology laboratory of the Department of General Psychology (University of Padova) in mixed-sex groups of 20-30 individuals ( $150 \mathrm{~L}$ in each tank). The aquaria each had a 14:10 h light to dark (L:D) photoperiod and an $18 \mathrm{~W}$ fluorescent light. Aquaria were provided with air filters, natural gravel, and live plants at a temperature of $25 \pm 1{ }^{\circ} \mathrm{C}$. Fish were fed daily twice: once with commercial food flakes and once with live brine shrimps (Artemia salina). Each subject was singly moved into a $50 \times 19 \times 32 \mathrm{~cm}$ tank in the week preceding our experiment. Four smaller conspecifics were inserted in the tank to reduce the possibility that social isolation might have affected the subjects' behavior in the two tasks. The local ethics committee of the University of Padova approved the study (permit number: 37/2016).

Fish were observed in two different tasks (presented according to a pseudorandom order): (a) a detour test to assess the degree of each subject's lateralization, and (b) a color discrimination task to assess their ability to learn a conditioned rule.

\subsection{Lateralization Test: Detour Test}

In this test, subjects typically swim along a runway until they encounter a dummy predator behind a barrier (Figure 1). Eye preference-and the corresponding left or right hemisphere that preferentially encodes the potential predator-is inferred by the subject's direction when leaving the runway $[17,34,35]$. 


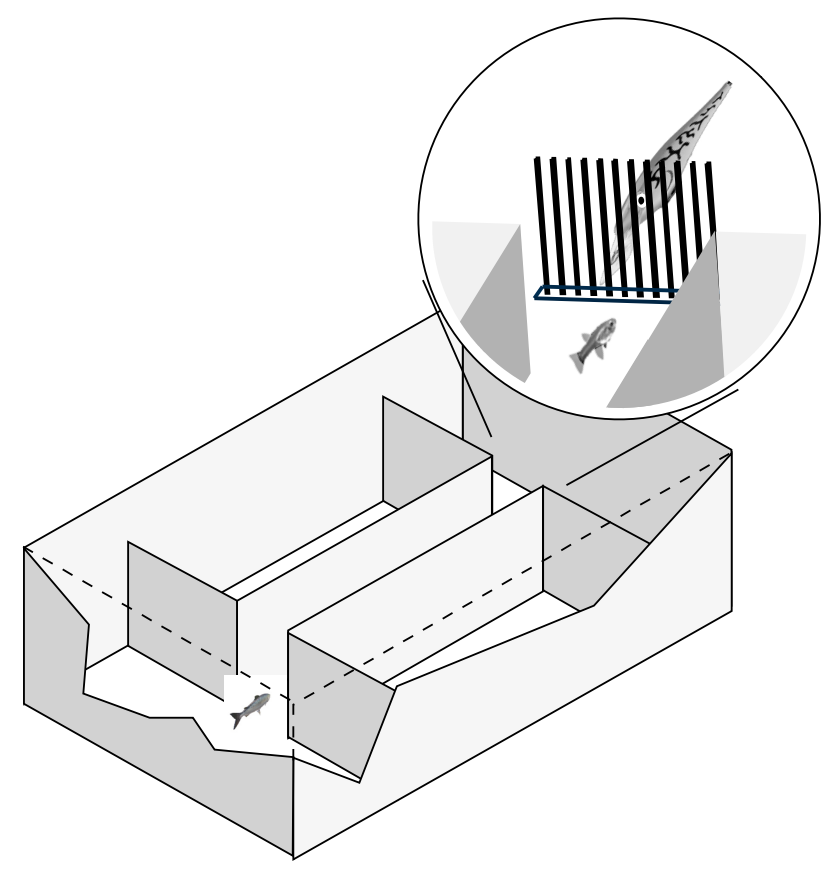

Figure 1. Detour test. A dummy predator was visible behind a barrier at both ends of the runway. The lateralization index was based on 20 observations for each subject.

\subsubsection{Stimuli and Apparatus}

The apparatus was a modified version used in previous studies of fish $[27,33]$ and consisted of a glass tank $(60 \times 94 \times 36 \mathrm{~cm})$ filled with $10 \mathrm{~cm}$ of water. A plastic runway $(7 \times 40 \mathrm{~cm})$ was placed in the middle, permitting subjects to encounter a barrier. Behind the barrier-a series of vertical yellow cylindrical plastic bars $(0.05 \mathrm{~cm}$ in diameter, spaced at $0.25 \mathrm{~cm}$ intervals $)$ that occupied $17 \times 17 \mathrm{~cm}-\mathrm{a}$ dummy predator (Rapala lure no. $18,18 \times 2.5 \mathrm{~cm}$ ) was visible at both ends of the runway. At the two short sides of the apparatus, we placed two $18 \mathrm{~W}$ fluorescent lamps to maximize the visibility of the dummy predators.

\subsubsection{Procedure}

A single subject was inserted in the middle of the runway. Then, by using a pair of fishnets, the subject was gently pushed toward the starting point. In this way, the subject started to swim along the runway until the dummy predator was visible. We recorded twenty consecutive trials. We used the percentage of left and right turns taken by the subject when leaving the runway as an index of lateralization, based on the following formula: (([number of rightward turns - number of leftward turns]/total number of turns) $\times 100$ ). This index is a continuous variable and fish with a positive score were classified as subjects with a right detour preference whereas individuals with a negative score were classified as subjects with a left detour preference. In the case of individuals turning rightward half of the time, we classified them as non-lateralized [27,33].

\subsection{Color Discrimination Task}

Color discrimination tasks are commonly used in operant conditioning studies to assess learning abilities [49-51]. Zebrafish were required to reach the positive stimulus (e.g., a green square), instead of the negative one (e.g., a blue square), to obtain a food reward.

\subsubsection{Apparatus and Stimuli}

We used an automated operant conditioning apparatus developed for zebrafish (Zantiks AD, Figure 2). The whole unit's size included the experimental chamber $(22 \times 30 \times 50 \mathrm{~cm}$, width $\times$ length $\times$ 
height), a computer, and the software $(C++$ language $)$. The chamber $(14 \times 20 \times 15 \mathrm{~cm})$ was made up of white plastic walls; the floor was made of transparent plastic. The chamber was filled with $8 \mathrm{~cm}$ of water. A computer screen $(16 \times 10 \mathrm{~cm})$ placed beneath the tank presented the stimuli in correspondence with one of the short walls. A wireless router allowed us to use a laptop to run the experiment and collect data. The integrated computer automatically detected the subject's position through an infrared camera placed above the chamber and an infrared source placed below the chamber. Zantiks scripts of the task are available in the Supplementary Materials.

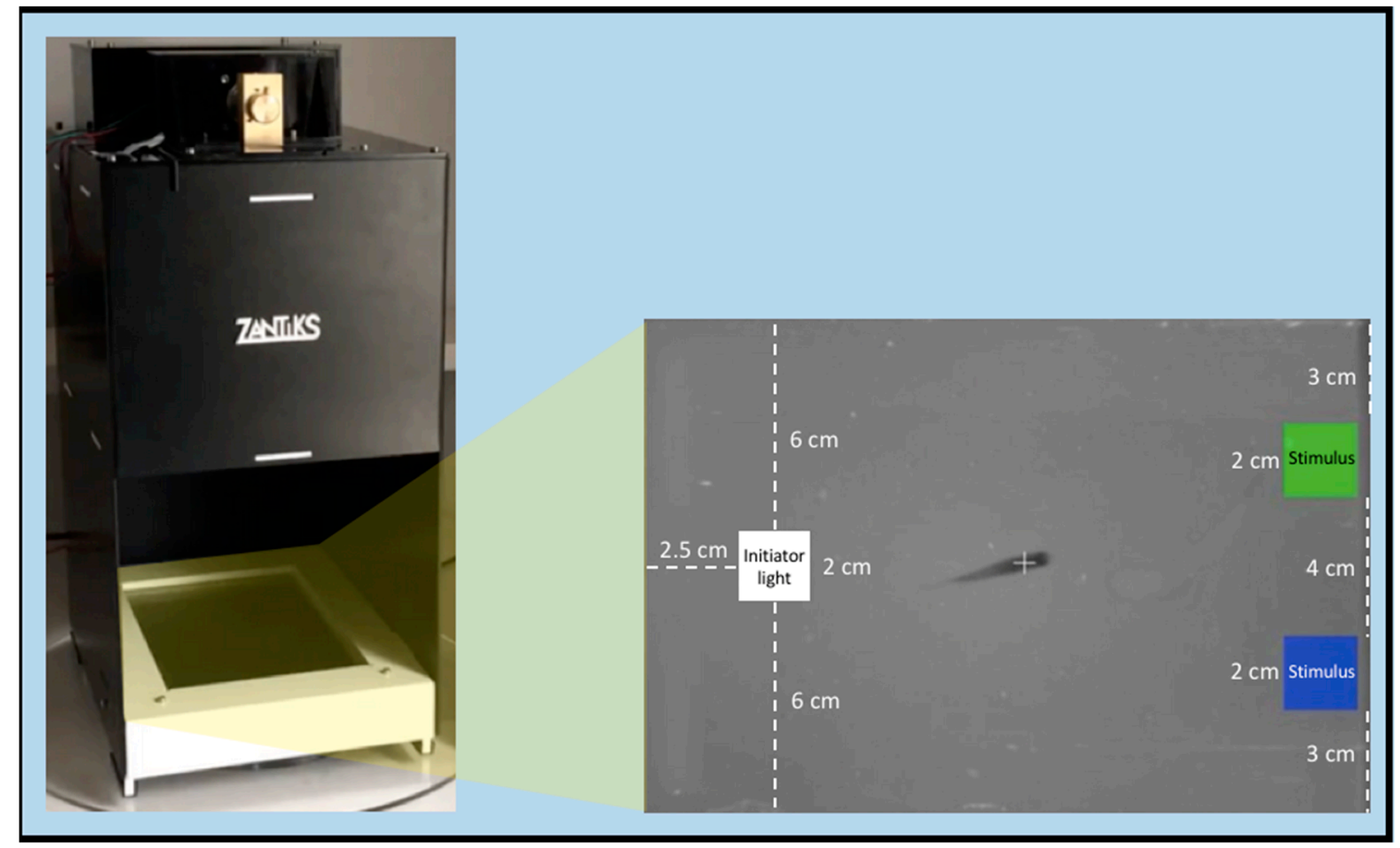

Figure 2. Operant conditioning chamber (Zantiks@) used in the color discrimination task. Stimuli were presented on the bottom of the tank. On the opposite side, we presented two rectangles differing in color (e.g., blue and green). A correct choice triggered the release of a food reward.

Stimuli $(2 \times 2 \mathrm{~cm})$ consisted of colored rectangles: red (RGB: 255, 0, 0), yellow (RGB: 255, 255, 0), green (RGB: 0, 255, 0), and blue (RGB: 0, 0, 255). An initiator white light rectangle (RGB: 255, 255, 255) appeared at the beginning of each trial.

\subsubsection{Procedure}

Pre-training: In this stage, we needed to ensure that the zebrafish learned how to trigger the presentation of the stimuli, select one stimulus, and then swim to the feeder and eat the reward. This phase enabled us to eliminate any eventual lack of color discrimination as a general failure to understand the sequence of events composing the trial.

Subjects were moved from their home tanks to the experimental chamber. The pre-training session started after 5 min of habituation and was characterized by 80 overall trials. Each trial started with a white rectangle $(2 \times 2 \mathrm{~cm})$ that served as an initiator light. This light was presented in correspondence with one short end of the chamber. The initiator light remained visible for a maximum of $10 \mathrm{~s}$; if not selected, the initiator light disappeared for the next $10 \mathrm{~s}$. As soon as a fish approached the initiator light by swimming above the white rectangle, a colored rectangle appeared on the opposite short wall. In the case of the discrimination of yellow vs. red, the colored rectangle was green; in the case of the discrimination of green vs. blue, the colored rectangle was red. The colored rectangle remained visible for a maximum of $10 \mathrm{~s}$. The food reward consisted of a $2 \mathrm{mg}$ portion of commercial flake food, GVG Sera(C), and was released above the initiator light every time the subject swam above the colored light. 
In the event of no selection of the colored square, the trial was not considered for the analysis and a time-out of $10 \mathrm{~s}$ was presented. Subjects completing at least 25 out of 80 trials in a single session started the next step.

Training: Fifty percent of the subjects were trained in yellow and red discrimination (50\% with red as a positive stimulus); and 50\% of them were trained in blue and green discrimination $(50 \%$ with blue as a positive stimulus). These specific contrasts were chosen because previous studies showed that zebrafish successfully discriminate between yellow and red, and between blue and green [49].

The experiment was run in a dark environment. As soon as the white initiator light appeared, the trial began. If a fish swam above the light within $10 \mathrm{~s}$, a choice between two different colored squares was given on the opposite side of the tank (see Figure 2 for measures). The interstimulus distance was equal to $4 \mathrm{~cm}$. As the stimuli appeared when subjects triggered the initiator light, placed at $15.5 \mathrm{~cm}$ from the stimuli, optical refraction might not have significantly affected the hue, saturation, or brightness of our target colors in any position of the experimental chamber [52]. In the case of the correct choice, we delivered the same food reward used in the pre-training phase in correspondence with the initiator light. On the contrary, if a fish selected the wrong alternative, the two stimuli disappeared, and the bottom of the tank became white until the beginning of next trial. If subjects did not select the initiator light within $10 \mathrm{~s}$, or did not select either stimulus, the stimuli disappeared, and the trial was considered to be an omission. Each training session included 100 trials. The stimulus position on the left-right axis was switched across trials according to a random sequence. The task ended when the fish reached 500 valid trials. (No omissions were included.)

As the data were normally distributed, we used parametric statistics (Kolmogorov-Smirnov on the overall performance of the training, $p=0.138$ ).

\section{Results}

Color discrimination task: a generalized linear mixed model (GLMM) was used to assess whether the performance differed among subjects. A significant inter-individual difference was found $\left(\chi^{2}(15)=529.57, p<0.001\right)$. In particular, binomial tests on the frequency of correct choices showed that 5 subjects out of $16(31 \%)$ selected the color associated with the food reward $(p<0.05)$. No difference in the proportion of choice towards the positive stimulus was found between fish tested in the discrimination between yellow and red and those tested in the discrimination between green and blue (yellow vs. red: $0.424 \pm 0.151$, blue vs. green: $0.498 \pm 0.118$; independent $t$-test, $t(14)=-1.096, p$ $=0.292, \mathrm{~d}=0.274)$. Therefore, we pooled the two groups for the subsequent analyses. To measure whether any side bias emerged throughout the training, we calculated the proportion of choices for the stimulus presented on the right side. The proportion of choice for the stimulus on the right side did not change as a function of trials (repeated measures of ANOVA, Greenhouse-Geisser correction, $\mathrm{F}(2.515,37.719)=1.788, p=0.173$, partial eta squared $\eta_{\mathrm{p}}{ }^{2}=0.106$, Figure 3$)$, meaning that the repeated presentation of stimuli on the left-right axis did not lead to the development of side biases per se. 


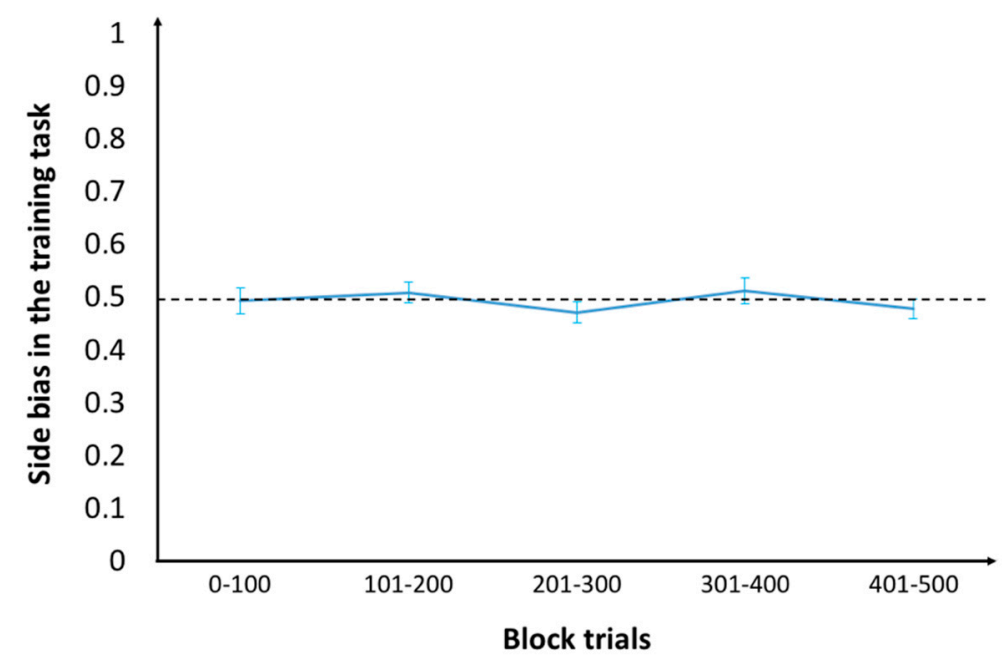

Figure 3. Proportion of choices for the right side of the tank in the color discrimination task. No side bias was developed throughout the 500 trials of the color discrimination task.

Correlation between the detour test and the color discrimination task: a positive correlation was observed between the performance in the detour test and the proportion of choices for the stimulus presented on the right in the color discrimination task $(\mathrm{r}(14)=0.921, p<0.001$, Bayes factor $<0.001$, Figure 4), meaning that the side bias observed in the training task was related to the subject's brain lateralization observed in the detour test. However, no correlation was found between the performance in the detour test and the proportion of correct choices in the training task $(\mathrm{r}(14)=0.181, p=0.503$, Bayes factor $=4.228$, Figure 5), meaning that non-lateralized individuals did not outperform lateralized ones in the present operant conditioning task.

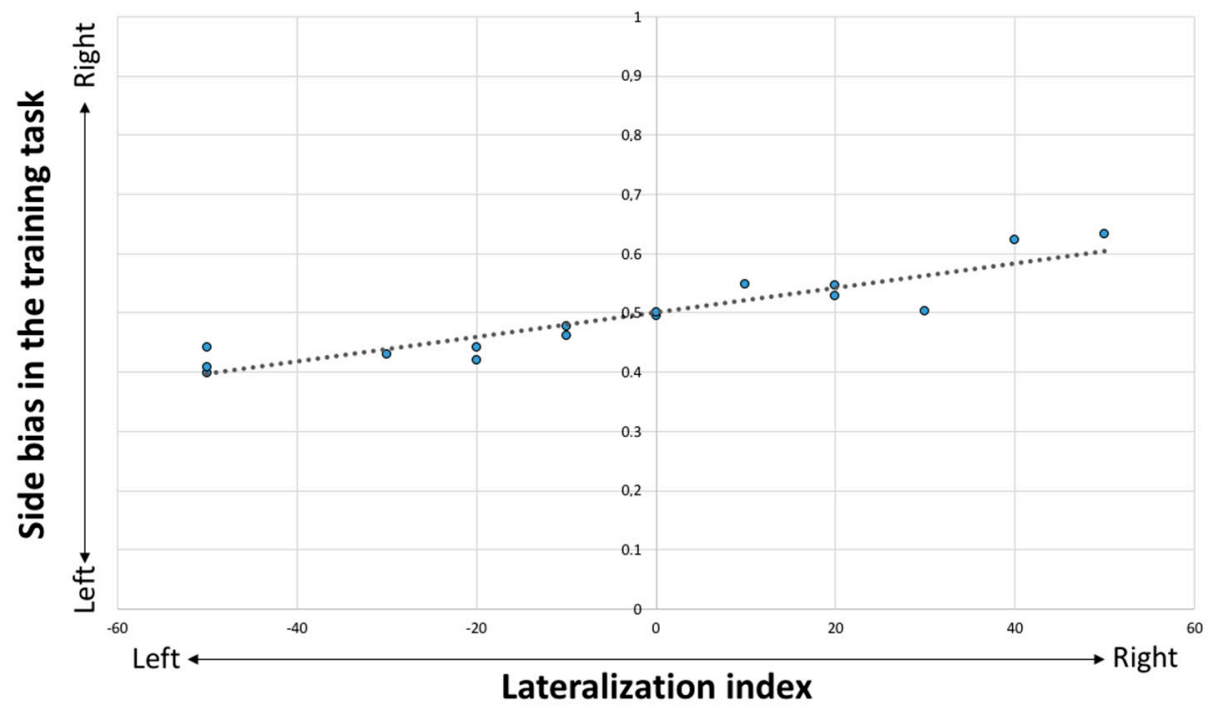

Figure 4. Positive correlation between the lateralization index and the proportion of choices for the right side in the operant conditioning task. Right detour fish tended to select the stimuli of the color discrimination task presented on the right; left detour fish tended to select the opposite stimulus (left). 


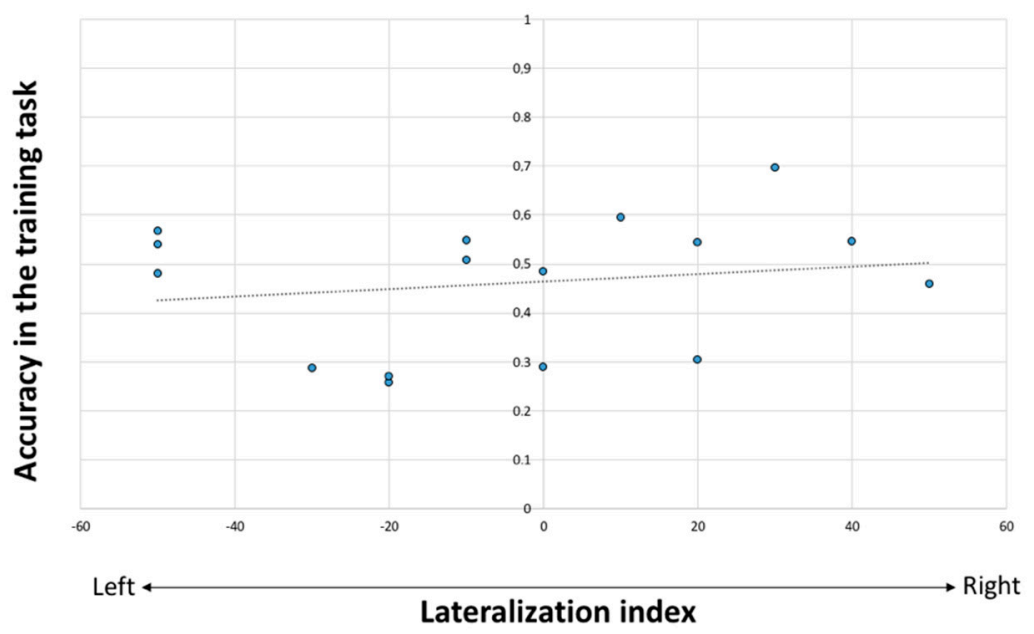

Figure 5. Correlation between the lateralization index and the overall accuracy in the operant conditioning task. Despite a clear side bias of lateralized fish, non-lateralized fish did not statistically outperform lateralized fish.

\section{Discussion}

We wondered whether brain lateralization impacts the performance of laboratory animals that undergo operant conditioning tasks based on binary choices. To achieve this goal, we used the detour test, one of the most established tests, to assess the direction and degree of brain lateralization, and correlated zebrafish behavior with the performance exhibited in an operant conditioning task requiring selection between one of two colors presented on the left-right axis. We found a strong positive correlation between brain lateralization and the tendency to select repeatedly the stimulus presented on one side of the tank. Our conclusion is supported by two different statistical perspectives: the $p$-value and Bayesian approaches.

Our result has important methodological implications for animal studies based on binary choices. Indeed, most of these studies do not preliminarily assess the degree of hemispheric specialization of their subjects. Therefore, the performance in binary choice tasks may be interpreted because of cognitive abilities or inabilities. We showed that lateralized individuals exhibit this bias from the beginning of the training, a fact that indicates a pre-existing bias rather than an acquired bias developed throughout the trials. Interestingly, we found that zebrafish could not inhibit their tendencies to swim to the preferred side of the experimental chamber even after an extensive training of 500 trials, in which the positive and the negative stimuli were presented randomly on the left-right axis. These subjects may have had the cognitive abilities to solve the color discrimination task, but they might not have been able to perform the correct choice when the correct stimulus was placed on the non-preferred side. This result calls for a cautious interpretation of binary choice tasks, particularly in the case of those studies in which animals are tested only once or twice, such as in free choice tests with subjects observed in their spontaneous preferences for biologically relevant stimuli [53-55]. In this case, it is difficult to establish whether the subjects have a lateralization bias, making data interpretation ambiguous.

The results of our study may be important in behavioral neuroscience because zebrafish are one of the most adopted animal models in genetics, neuroscience, and developmental biology [34,35]. To assess their performance in perceptual-cognitive tasks, many studies used free choice tests $[37,43,56]$ or operant conditioning studies [36,39]. In either case, binary choices are often presented to subjects and the differential performance has been read as the existence of inter-individual variability in the perceptual-cognitive skill under investigation [36,40].

The use of a preliminary test on the brain lateralization of subjects could solve this issue. We suggest two potential solutions. One consists of discarding those subjects who exhibit a robust lateralization bias in the detour test. This would lead to including in the final sample only those fish that could respond to the stimuli. However, this would bring researchers to test a specific subsample of fish: the 
poorly lateralized ones. There is evidence that strongly and poorly lateralized fish differ for several cognitive factors, including the capacity to perform dual tasks [57], numerical discrimination [58], and spatial tasks [33]. In this sense, testing a sample made by non-lateralized individuals would prevent researchers from generalizing the conclusions to the whole population of zebrafish. Alternatively, detour tests might be useful to identify if there is a large percentage of strongly lateralized individuals. If so, subjects could undergo binary choices with stimuli arranged on the vertical axis (one above and the other below). This experimental strategy, of course, would skip the left-right bias, but could be adopted only after ensuring that the species under investigation does not have a spontaneous preference for selecting a stimulus placed on either the top or bottom of the experimental apparatus (a fact that might represent another side bias that affects the validity of the binary choice tasks).

If strongly lateralized individuals are expected to exhibit strong side bias choice, we should expect non-lateralized individuals to be advantaged in tasks that require learning a discriminative rule between stimuli arranged on the left-right axis. There is indeed evidence that, in some cases, non-lateralized fish outperform lateralized ones; non-lateralized goldbelly topminnows are more accurate when required to bisect a line or to transfer visual information quickly between the two halves of the brain before choosing which shoal to join [33]. We have not found a correlation between the degree of lateralization and the accuracy in the operant conditioning task, but we cannot exclude that an advantage for non-lateralized ones may emerge in other cognitive tasks or other experimental conditions. We must note that a large inter-individual variability in the subjects' performance of the color discrimination task was found, and the overall performance of subjects in our color discrimination task was low. We cannot exclude the possibility that the results of the correlational analyses reported here would not persist in a population of well-trained fish. Developing finer procedures for testing perceptual-cognitive skills in zebrafish is fundamental, given the brain imaging possibilities available in larvae. Such investigation would permit, for instance, mapping behavioral lateralization (such as the one tested here) onto the neural circuits of a zebrafish brain, or to determine neural circuits underlying the emergence of side biases. However, it is worth noting that the subjects' percentage for selecting the positive stimulus at the end of our training $(31 \%)$ was similar to the percentage of zebrafish reaching the learning criterion in other perceptual-cognitive tasks $[36,59]$. This suggests that, rather than assuming that our training procedure was largely ineffective in this species, the cognitive skills of this important animal model could barely be shaped by extensive training, compared with other fish species (e.g., guppies [60], redtail splitfins [61], and angelfish [62]).

In conclusion, we found that the behavior exhibited in a test measuring brain lateralization seems to be predictive of the side bias exhibited by zebrafish in binary choices. Lateralized individuals tend to turn to a preferred side of the experimental tank regardless of extensive training, a fact that makes it difficult to understand whether these individuals have the cognitive abilities to solve the task.

Supplementary Materials: The following are available online at http://www.mdpi.com/2073-8994/12/8/1294/s1.

Author Contributions: Conceptualization, M.E.M.P. and C.A.; Data curation, A.P.; Funding acquisition, M.E.M.P.; Investigation, M.D; Methodology, A.P.; Writing—original draft, M.E.M.P., A.P., M.D. and C.A. All authors have read and agreed to the published version of the manuscript.

Funding: This study was supported by 'Stars@unipd' grant (acronym: MetaZeb) from the University of Padova to M.E.M.P.

Acknowledgments: We performed the present work within the scope of the research grant Dipartimenti di Eccellenza entitled "Innovative methods or technologies for assessment, intervention, or enhancement of psychological functions (cognitive, emotional or behavioral)".

Conflicts of Interest: The authors declare no conflict of interest.

\section{References}

1. Parrish, A.E.; Beran, M.J. When less is more: Like humans, chimpanzees (Pan troglodytes) misperceive food amounts based on plate size. Anim. Cogn. 2014, 17, 427-434. [CrossRef] 
2. Lucon-Xiccato, T.; Miletto Petrazzini, M.E.; Agrillo, C.; Bisazza, A. Guppies discriminate between two quantities of food items but prioritize item size over total amount. Anim. Behav. 2015, 107, 183-191. [CrossRef]

3. Santacà, M.; Agrillo, C. Perception of the Müller-Lyer illusion in guppies. Curr. Zool. 2020, 66, $205-213$. [CrossRef] [PubMed]

4. Cantlon, J.; Brannon, E. Basic math in monkeys and collegestudents. PLoS Biol. 2007, 5, e328. [CrossRef] [PubMed]

5. Sovrano, V.A.; Bisazza, A.; Vallortigara, G. Modularity as a fish (Xenotoca eiseni) views it: Conjoining geometric and nongeometric information for spatial reorientation. J. Exp. Psych. Anim. Behav. Proc. 2003, 29, 199-210. [CrossRef] [PubMed]

6. Robins, A.; Rogers, L.J. Complementary and lateralized forms of processing in Bufo marinus for novel and familiar prey. Neurobiol. Learn. Mem. 2006, 86, 214-227. [CrossRef] [PubMed]

7. Giljov, A.N.; Karenina, K.A.; Malashichev, Y.B. An eye for a worm: Lateralisation of feeding behaviour in aquatic anamniotes. Laterality 2009, 14, 273-286. [CrossRef]

8. Peirce, J.W.; Leigh, A.E.; Kendrick, K.M. Configurational coding, familiarity and the right hemisphere advantage for face recognition in sheep. Neuropsychologia 2000, 38, 475-483. [CrossRef]

9. Bortot, M.; Agrillo, C.; Avarguès-Weber, A.; Bisazza, A.; Miletto Petrazzini, M.E.; Giurfa, M. Honeybees use absolute rather than relative numerosity in number discrimination. Biol. Lett. 2019, 15, 20190138. [CrossRef]

10. Adámková, J.; Svoboda, J.; Benediktová, K.; Martini, S.; Nováková, P.; Tůma, D.; Burda, H. Directional preference in dogs: Laterality and "pull of the north". PLOS ONE 2017, 12, e0185243. [CrossRef]

11. Bisazza, A.; De Santi, A.; Bonso, S.; Sovrano, V.A. Frogs and toads in front of a mirror: Lateralisation of response to social stimuli in tadpoles of five anuran species. Behav. Brain Res. 2002, 134, 417-424. [CrossRef]

12. Santacà, M.; Agrillo, C. Two halves are less than the whole: Evidence of a length bisection bias in fish (Poecilia reticulata). PLoS ONE 2020, 15, e0233157. [CrossRef]

13. Gierszewski, S.; Bleckmann, H.; Schluessel, V. Cognitive abilities in Malawi cichlids (Pseudotropheus sp.): Matching-to-sample and image/mirror-image discriminations. PLoS ONE 2013, 8, e57363. [CrossRef] [PubMed]

14. Kuba, M.J.; Byrne, R.A.; Burghardt, G.M. A new method for studying problem solving and tool use in stingrays (Potamotrygon castexi). Anim. Cogn. 2010, 13, 507-513. [CrossRef] [PubMed]

15. Lebovich, L.; Darshan, R.; Lavi, Y.; Hansel, D.; Loewenstein, Y. Idiosyncratic choice bias naturally emerges from intrinsic stochasticity in neuronal dynamics. Nat. Hum. Behav. 2019, 3, 1190-1202. [CrossRef]

16. Andrade, C.; Alwarshetty, M.; Sudha, S.J.; Suresh Chandra, J. Effect of innate direction bias on T-maze learning in rats: Implications for research. J. Neurosci. Methods 2001, 110, 31-35. [CrossRef]

17. Danisman, E.; Bshary, R.; Bergmüller, R. Do cleaner fish learn to feed against their preference in a reverse reward contingency task? Anim. Cogn. 2010, 13, 41-49. [CrossRef] [PubMed]

18. Agrillo, C.; Parrish, A.E.; Beran, M.J. Do primates see the solitaire illusion differently? A comparative assessment of humans (Homo sapiens), chimpanzees (Pan troglodytes), rhesus mon-keys (Macaca mulatta), and capuchin monkeys (Cebus apella). J. Comp. Psychol. 2014, 128, 402-413. [CrossRef]

19. Alves, C.; Chichery, R.; Boal, J.G.; Dickel, L. Orientation in the cuttlefish Sepia officinalis: Response versus place learning. Anim. Cogn. 2007, 10, 29-36. [CrossRef]

20. Miletto Petrazzini, M.E.; Wynne, C.D. What counts for dogs (Canis lupus familiaris) in a quantity discrimination task? Behav. Proc. 2016, 122, 90-97. [CrossRef]

21. Miletto Petrazzini, M.E.; Mantese, F.; Prato Previde, E. Food quantity discrimination in puppies (Canis lupus familiaris). Anim. Cogn. 2020, 23, 703-710. [CrossRef] [PubMed]

22. Collins, R.L. When left-handed mice live in right-handed world. Science 1975, 187, 181-184. [CrossRef] [PubMed]

23. Ayroles, J.F.; Buchanan, S.M.; O’Leary, C.; Skutt-Kakaria, K.; Grenier, J.K.; Clark, A.G.; Hartl, D.L.; de Bivort, B.L. Behavioral idiosyncrasy reveals genetic control of phenotypic variability. Proc. Natl. Acad. Sci. USA 2015, 112, 6706-6711. [CrossRef] [PubMed]

24. Iigaya, K.; Ahmadian, Y.; Sugrue, L.P.; Corrado, G.S.; Loewenstein, Y.; Newsome, W.T.; Fusi, S. Deviation from the matching law reflects an optimal strategy involving learning over multiple timescales. Nat. Commun. 2019, 10, 1466. [CrossRef] 
25. Frasnelli, E.; Ponte, G.; Vallortigara, G.; Fiorito, G. Visual lateralization in the cephalopod mollusk Octopus vulgaris. Symmetry 2019, 11, 1121. [CrossRef]

26. Regaiolli, B.; Spiezo, C.; Hopkins, W.D. Asymmetries in mother-infant behaviour in Barbary macaques (Macaca sylvanus). PeerJ 2018, 6, e4736. [CrossRef]

27. Dadda, M.; Agrillo, C.; Bisazza, A.; Brown, C. Laterality enhances numerical skills in the guppy, Poecilia reticulata. Front. Behav. Neurosci. 2015, 9, 285. [CrossRef]

28. Bisazza, A.; Rogers, L.J.; Vallortigara, G. The origins of cerebral asymmetry: A review of evidence of behavioural and brain lateralization in fishes, reptiles and amphibians. Neurosci. Biobehav. Rev. 1998, 22, 411-426. [CrossRef]

29. Güntürkün, O.; Ströckens, F.; Ocklenburg, S. Brain lateralization: A comparative perspective. Physiol. Rev. 2020, 100, 1019-1063. [CrossRef]

30. Ströckens, F.; Güntürkün, O.; Ocklenburg, S. Limb preferences in non-human vertebrates. Laterality 2013, 18, 536-575. [CrossRef]

31. Versace, E.; Caffini, M.; Werkhoven, Z.; de Bivort, B. Individual, but not population asymmetries, are modulated by social environment and genotype in Drosophila melanogaster. Sci. Rep. 2020, 10, 4480. [CrossRef] [PubMed]

32. Miletto Petrazzini, M.E.; Sovrano, V.; Vallortigara, G.; Messina, A. Brain and behavioral asymmetry: A lesson from fish. Front. Neuroanat. 2020, 14, 11. [CrossRef] [PubMed]

33. Dadda, M.; Zandonà, E.; Agrillo, C.; Bisazza, A. The costs of hemispheric specialization in a fish. Proc. R. Soc. B Biol. Sci. 2009, 276, 4399-4407. [CrossRef] [PubMed]

34. Bandmann, O.; Burton, E.A. Genetic zebrafish models of neurodege-nerative diseases. Neurobiol. Dis. 2010, 40, 58-65. [CrossRef] [PubMed]

35. Langenau, D.M.; Zon, L.I. The zebrafish: A new model of T-cell and thymic development. Nat. Rev. 2005, 5, 307-317. [CrossRef] [PubMed]

36. Agrillo, C.; Miletto Petrazzini, M.E.; Tagliapietra, C.; Bisazza, A. Inter-specific differences in numerical abilities among teleost fish. Front. Psychol. 2012, 3, 483. [CrossRef]

37. Potrich, D.; Sovrano, V.A.; Stancher, G.; Vallortigara, G. Quantity discrimination by zebrafish (Danio rerio). J. Comp. Psychol. 2015, 129, 388-393. [CrossRef]

38. Potrich, D.; Rugani, R.; Sovrano, V.A.; Regolin, L.; Vallortigara, G. Use of numerical and spatial information in ordinal counting by zebrafish. Sci. Rep. 2019, 9, 18323. [CrossRef]

39. Baratti, G.; Potrich, D.; Sovrano, V.A. The environmental geometry in spatial learning by zebrafish (Danio rerio). Zebrafish 2020, 17, 131-138. [CrossRef]

40. Gori, S.; Agrillo, C.; Dadda, M.; Bisazza, A. Do fish perceive illusory motion. Sci. Rep. 2014, 4, 6443. [CrossRef]

41. Santacà, M.; Lucon-Xiccato, T.; Agrillo, C. The Delboeuf illusion's bias in food choice of teleost fishes: An interspecific study. Anim. Behav. 2020, 164, 105-112. [CrossRef]

42. Facchin, L.; Burgess, H.A.; Siddiqi, M.; Granato, M.; Halpern, M.E. Determining the function of zebrafish epithalamic asymmetry. Philos. Trans. R. Soc. B Biol. Sci. 2009, 364, 1021-1032. [CrossRef] [PubMed]

43. Stennett, C.R.; Strauss, R.E. Behavioural lateralization in zebrafish and four related species of minnows (Osteichthyes: Cyprinidae). Anim. Behav. 2010, 79, 1339-1342. [CrossRef]

44. Hata, H.; Hori, M. Inheritance patterns of morphological laterality in mouth opening of zebrafish, Danio rerio. Laterality 2001, 17, 741-754. [CrossRef]

45. Brown, C.; Western, J.; Braithwaite, V.A. The influence of early experience on, and inheritance of cerebral lateralization. Anim. Behav. 2007, 74, 231-238. [CrossRef]

46. Domenici, P.; Allan, B.; McCormick, M.I.; Munday, P.L. Elevated carbon dioxide affects behavioural lateralization in a coral reef fish. Biol. Lett. 2012, 8, 78-81. [CrossRef]

47. Sovrano, V.A.; Bisazza, A.; Vallortigara, G. Modularity and spatial reorientation in a simple mind: Encoding of geometric and nongeometric properties of a spatial environment by fish. Cognition 2002, 85, B51-B59. [CrossRef]

48. Agrillo, C.; Miletto Petrazzini, M.E.; Bisazza, A. Numerical abilities in fish: A methodological review. Behav. Proc. 2007, 141, 161-171. [CrossRef]

49. Oliveira, J.; Silveira, M.; Chacon, D.; Luchiari, A. The zebrafish world of colors and shapes: Preference and discrimination. Zebrafish 2015, 12, 166-173. [CrossRef] 
50. Savage, A.; Dronzek, L.A.; Snowden, C.T. Color discrimination by the cotton-top tamarin (Saguinus oedipus oedipus) and its relation to fruit coloration. Folia Primatol. 1987, 49, 57-69. [CrossRef]

51. Giurfa, M. Conditioning procedure and color discrimination in the honeybee Apis mellifera. Naturwissenschaften 2004, 91, 228-231. [CrossRef] [PubMed]

52. Dunn, T.W.; Fitzgerald, J.E. Correcting for physical distortions in visual stimuli improves reproducibility in zebrafish neuroscience. eLife 2020, 9, e53684. [CrossRef] [PubMed]

53. Uller, C.; Lewis, J. Horses (Equus caballus) select the greater of two quantities in small numerical contrasts. Anim. Cogn. 2009, 12, 733-738. [CrossRef] [PubMed]

54. Bánszegi, O.; Urrutia, A.; Szenczi, P.; Hudson, R. More or less: Spontaneous quantity discrimination in the domestic cat. Anim. Cogn. 2016, 19, 879-888. [CrossRef] [PubMed]

55. Uller, C.; Jaeger, R.; Guidry, G.; Martin, C. Salamanders (Plethodon cinereus) go for more: Rudiments of number in an amphibian. Anim. Cogn. 2003, 6, 105-112. [CrossRef]

56. Pritchard, V.L.; Lawrence, J.; Butlin, R.K.; Krause, J. Shoal size in zebrafish, Danio rerio: The influence of shoal size and activity. Anim. Behav. 2001, 62, 1085-1088. [CrossRef]

57. Dadda, M.; Bisazza, A. Does brain asymmetry allow efficient performance of two simultaneous tasks? Anim. Behav. 2006, 72, 523-529. [CrossRef]

58. Gatto, E.; Agrillo, C.; Brown, C.; Dadda, M. Individual differences in numerical skills are influenced by brain lateralization in guppies (Poecilia reticulata). Intelligence 2019, 74, 12-17. [CrossRef]

59. Gatto, E.; Lucon-Xiccato, T.; Bisazza, A.; Manabe, K.; Dadda, M. The devil is in the detail: Zebrafish learn to discriminate visual stimuli only if salient. Behav. Proc.. under review.

60. Bisazza, A.; Agrillo, C.; Lucon-Xiccato, T. Extensive training extends numerical abilities of guppies. Anim. Cogn. 2014, 7, 1413-1419. [CrossRef]

61. Sovrano, V.A.; Bisazza, A. Perception of subjective contours in fish. Perception 2009, 38, 579-590. [CrossRef] [PubMed]

62. Miletto Petrazzini, M.E.; Agrillo, C.; Izard, V.; Bisazza, A. Do humans (Homo sapiens) and fish (Pterophyllum scalare) make similar numerosity judgments? J. Comp. Psychol. 2016, 130, 380-390. [CrossRef] [PubMed]

(C) 2020 by the authors. Licensee MDPI, Basel, Switzerland. This article is an open access article distributed under the terms and conditions of the Creative Commons Attribution (CC BY) license (http://creativecommons.org/licenses/by/4.0/). 